\title{
O VIVO INCOMENSURÁVEL: ENTRE CIÊNCIA E INCONSCIENTE $^{1}$
}

François Ansermet

Pensar o laço entre neurociências e psicanálise obriga a pensar no incomensurável: pensar a partir do "nada em comum", para além de toda traduçãa, superposição, analogia redutora ou relação causa-efeito simplista. Senão permaneceremos nos pulos da pulga. Se pegarmos uma pulga, batermos uma palma: ela salta. Se the tirarmos uma pata, depois duas, depois três, ela salta cada vez menos longe. Se lhe tirarmos todas as patas, ela não salta de modo algum tal como quando batemos palma. Conclusão: a audição está nas patas!

Há, com efeito, sempre o mesmo risco na interpretação das funções do cérebro: de ser tomado em uma relação estrutura-função simplista, linear, contínua, sem resto culminando em um falso raciocínio malgrado suas roupagens de evidência.

\section{UMA CAUSALIDADE "LÓGICA”}

causalidade orgânica cai na mesma cilada de uma suposta causalidade natural
exclusiva, que rejeita uma "causalidade lógica" como a nomeia Lacan, uma
causalidade que implica o logos: "Não é entre o físico e o psíquico que o corte deveria ser feito, mas entre o psíquico e o lógico" (Lacan, 1958/2003, p. 173; Lacan, 1967/2001, p. 45a). ${ }^{2}$ A linguagem implica uma causalidade lógica diferente da causalidade neuronal. E sobretudo a linguagem é exterior, ela nos precede, já está lá em nosso nascimento e sobreviverá além de nós. A linguagem é outra forma do vivo diferente do vivo neuronal - um vivo tal como Lacan toma emprestado da metáfora da aranha: "O aparelho linguageiro está aí em algum lugar sobre o cérebro como uma aranha” (Lacan, 2001, p. 45b). É assim que se deveria passar das neurociências para as logociências (Ansermet, 2002, pp. 376, 384). Compreendendo que a linguagem é justamente o que faz com que "isso sonha, isso ri, isso rateia" e faz com que haja o inconsciente e o sujeito tomados nos desfiladeiros do desejo (Lacan, 1968/2005, p. 10).

1 Tradução de Lucia M. de Lima Mello, revisão de Soraia Maciel Moreira Mouls. Artigo originalmente publicado em francês por Ansermet, F. (2019, novembre). Le vivant incommensurable: entre science et l'inconscient. Mental, Revue Internacionale de Psychanalyse, 40, 63-67.

2 A primeira data indica o ano de publicação da obra, e a segunda, a edição consultada pelo autor, a qual somente será pontuada na primeira citação da obra no texto. Nas seguintes, será registrada apenas a data de publicação original. 
Mas não somente: há ainda o gozo do vivo. Se a causalidade do logos constitui o que é próprio do bio-"lógico", há também outro termo, o bios, o vivo. Não se pode separar nem o logos nem o bios do biológico - e é o que indica paradoxalmente $\mathrm{o}$ inconsciente em suas duas vertentes: o inconsciente lógico e o inconsciente de gozo, como foi diferenciado por Jacques-Alain Miller (Miller, 2016, p. 19a). Daí também decorre o título de nossa sequência: o inconsciente e o vivo, tudo em comum.

\section{O INCONSCIENTE OU O REAL?}

O inconsciente é primeiramente um produto da cura. Um inconsciente que nos mostra de início uma hiância - que se vincula a um "real que bem pode, ele sim, não ser determinado" que nos conduz além do logos (Lacan, 1985, p. 27). Talvez aí se encontre o vivo como tal. Em todo caso, sob a forma do impossível que resiste no logos. Como diz Lacan, na análise, situa-se "o lugar lógico do impossível” e, como ele o precisa, é aí que o real surge (Lacan, 1992, p. 154).

A análise não toca somente em uma ausência de saber (l'insu): ela toca também no real. É assim que Lacan coloca em jogo o real mais que o inconsciente. Donde, por contraste com o inconsciente transferencial, o conceito de inconsciente real destacado por Miller, a partir do Seminário XXIII de Lacan: "O que busca Lacan no fim de seu Seminário é um outro modo, uma outra perspectiva de inconsciente que implica o inconsciente real” (Miller, 2006, p. 9).

A ciência, em seu projeto, gostaria de poder tratar o real por suas fórmulas. Mas, quanto mais ela o trata, mais ela o produz. Nisso, a ciência, como toda prática simbólica, encontra a falha estrutural do simbólico, ao querer recobrir todo o real. É talvez aí que, paradoxalmente, o real da ciência encontra o real da psicanálise, salvo que a psicanálise não recua ante o real, contrariamente à ciência, que quer incessantemente continuar a reabsorvê-lo.

\section{PARA SAIR DA ILUSÃO}

É assim que as ciências, em particular as neurociências, devem rejeitar o real para avançar, para se dar a ilusão de avançar. Se Freud via na ciência o Futuro de uma ilusão, hoje se é atingido pela ciência como ilusão, como religião, em todo caso, em algumas de suas versões como as neurociências cognitivas - que tocam, às vezes, o sofisma à custa da crença em seu paradigma. Como aquele das bases biológicas dos transtornos psíquicos. Primeira proposição: admite-se que existam transtornos psíquicos. Segunda proposição: coloca-se a hipótese de 
que os transtornos psíquicos teriam uma base biológica. Terceira proposição: demonstra-se ou pensa-se demonstrar essa base biológica. Quarta proposição: se eles têm uma base biológica, então esses fenômenos não são psíquicos. Donde a conclusão: logo não existem transtornos psíquicos.

A ideia de bases biológicas está no fundamento do risco reducionista que constitui o impasse das neurociências contemporâneas. Para sair desse impasse, seria preciso ainda distinguir as propriedades biológicas dos estados psíquicos. As propriedades biológicas que permitem a memória não têm nada a ver com a memória. $\mathrm{O}$ mesmo ocorre com o inconsciente. Se não se consegue fazer essa distinção entre propriedades e estados, fica-se no impasse. Falta uma revolução epistemológica à neurociência.

Em todo caso, é preciso compreender que o reducionismo das bases biológicas caminha na contramão de certos avanços das ciências, como o sugere a evidência da instabilidade genética e da plasticidade (Ansermet \& Prochiantz, 2017, pp. $146,160)$. O sujeito inscreve traços mais do que deles resulta. Isso procede antes da descontinuidade do que da continuidade. Jamais se utiliza, por duas vezes, o mesmo cérebro. Tomados em uma mudança permanente, seríamos, de início, biologicamente determinados para não sermos completamente biologicamente determinados (Ansermet \& Magistretti, 2004). Determinados para não ser.

Por que a corrente reducionista das neurociências não extrai as consequências desses avanços? De onde vem essa resistência ante o que não se quer reconhecer - e que, entretanto, já se sabia? Dante o dizia a respeito da relação entre a língua e a natureza: "A obra da natureza é que o homem fala, mas, por assim dizer, a natureza deixa depois fazer com isso o que lhe agrada" (Dante, 1992). $\mathrm{O}$ vivo faz com que o homem seja inacabado, temporal e instável, o que lhe oferece a possibilidade de se reinventar incessantemente, para além de toda base supostamente biológica: de se inventar a partir do vivo, de se inventar diferente, imprevisível.

\section{A REJEIÇÃO AO VIVO}

De onde vem esse pendor para o reducionismo nas neurociências? Talvez pelo fato de que é preciso evacuar muitas coisas para que seu modelo funcione: ser redutor até abordar o cérebro rejeitando o vivo. Assim como a morte.

O cérebro das neurociências é um cérebro ideal, homeostático, regulado. Como um tal cérebro tão regulado pode produzir um humano tão desregulado? É uma contradição significativa das neurociências não abordar o homem desregulado em proveito de um homem neuronal, ideal, que não parece em nada com o 
homem tal qual ele é. O homem desregulado é rejeitado. Não é encontrado senão no registro das patologias, ao ponto de vê-las cada vez mais ampliadas, frequentes, até uma patologização da condição humana atrás da qual se corre coletando múltiplos dados, até mesmo através de smartfones, consideradas em todas as formas de estratégias digitais que dividem o sujeito feito objeto no infinito do big data.

A rejeição ao vivo como a rejeição ao sujeito está na base desse impasse nas neurociências, uma rejeição do inconsciente, tomado do lado do vivo, do inconsciente de puro gozo e não somente de pura lógica. Não há apenas a linguagem que parasita o cérebro, há também o gozo! Estamos diante de um duplo parasitismo: "da linguagem sobre o vivo, do vivo sobre a linguagem" - do gozo produzido pela via do significante (Lacan, 1975-1976, p. 95).

Trata-se, em todo caso, de colocar em evidência o laço entre o inconsciente e o vivo. $\mathrm{O}$ que passa, como propôs Miller, pelo fato de estabelecer a equivalência entre pulsão e inconsciente - uma equivalência que faz com que o falasser lacaniano venha a substituir o inconsciente freudiano (Miller, 2016, p. 19). Ao mesmo tempo, o binarismo entre inconsciente e pulsão - entre inconsciente e vivo - desaparece.

Inversamente, a constatação é que fazemos face à rejeição ao vivo no campo das neurociências, mesmo quando essas se apresentam como ciências do vivo. Uma rejeição ao vivo que encontra seu cumprimento no campo da inteligência artificial, até as fabricações contemporâneas dos robôs aos quais são dadas formas androides, uma fabricação artificial, criada sem ser procriada, sem a necessidade de passar por um corpo que curto circuita o vivo, ao imitá-lo.

\section{UMA PERSPECTIVA MELANCÓLICA}

O corpo nas neurociências - em todo caso, nessa visão cada vez mais computadorizada, mas também quando se supõe mecanismos neurocognitivos inteiramente regulados - tende para a concepção de um corpo sem o vivo que incomoda, sem a pulsão nem o inconsciente.

Mas não se trata somente de uma rejeição ao vivo, trata-se também de uma rejeição à morte. $\mathrm{O}$ vivo e a morte são ambos desconsiderados atrás de uma visão homeostática, idealizada, eternizada do cérebro.

Poderíamos aproximar essa paradoxal exclusão do vivo de uma perspectiva melancólica. Poderíamos até mesmo forçar a analogia até a síndrome de Cotard, que descreve aqueles que se imaginam sem corpo, sem órgão e até mesmo sem cérebro. 
Rejeitando o vivo e a morte, as neurociências contemporâneas seriam tomadas assim na perspectiva de uma espécie de "imortalidade melancólica" em todo caso, em sua versão idealizada que visa se tornar o modelo de todo fenômeno humano, entre a psiquiatria, a pedagogia, mas também a economia, até mesmo a teologia, com a neuro-teologia, a lista das áreas às quais se acrescentam o prefixo neuro tende a se tornar infinita. Como o que é rejeitado retornará, tal é a questão (Starobinski, 2012, pp. 471-498).

Visar a um suposto domínio do vivo é se submeter ao risco de Títono na Odisseia (Vernant, 1999, p. 144). Quando Aurora pede a seu amante Títono vida eterna, como as verdades eternas, a-históricas das neurociências cognitivas - ela esquece de pedir para ele a juventude eterna: ele se torna cada vez mais velho, encarquilhado como um inseto [. . .] cada vez mais horrível de se ver, insuportável: é o que ameaça as neurociências se elas continuarem a evacuar o vivo.

É importante compreender que a psicanálise, contrariamente às neurociências, não evacua o vivo. É assim que, de maneira inesperada, poder-se-ia ver a psicanálise antes como um porvir das neurociências do que ser enterrada por elas. 


\section{REFERÊNCIAS}

Ansermet, F. (2002). Des neurociences aux logosciences. Qui sont vos psychanalystes? Paris: Seuil.

Ansermet, F., \& Magistretti, P. (2004). À chacun son cerveau: plasticité neuronale et inconscient. Paris: Odile Jacob.

Ansermet, F., \& Prochiantz, A. (2017, septembre). On ne voit rien? La Cause du désir. L’objet regard, (esp), 146-160.

Dante. (1992). Le paradis XXVI. J. Risset (Trad.), La Divine Comédie. (vers 130-132). Paris: Flammarion.

Lacan, J. (1958/2003). A psicanálise verdadeira e a falsa. In Outros escritos. (pp. 173-182). Rio de Janeiro: Zahar, 2003. (Publicado originalmente em 1958).

Lacan, J. (1967/2001). Place, origine et fin de mon enseignement. In J.-A. Miller (Ed.), Mon enseignement. (pp. 9-73). Paris: Seuil, 2001. (Publicado originalmente em 1967).

Lacan, J. (1968/2005). Mon enseignement, sa nature et ses fins. In J.-A. Miller (Ed.), Mon enseignement. (pp. 75-112). Paris: Seuil, 2005. (Publicado originalmente em 1968).

Lacan, J. (1975-1976). Le séminaire, livre XXIII, Le sinthome. Paris: Seuil.

Lacan, J. (1985). O seminário, livro XI: os quatro conceitos fundamentais da psicanálise. Rio de Janeiro: Jorge Zahar.

Lacan, J. (1992). O seminário, livro XVII: o avesso da psicanálise. Rio de Janeiro: Jorge Zahar.

Miller, J.-A. (2006, décembre). L'inconscient réel. Quarto, 88-89, 6-11.

Miller, J.-A. (2016). O inconsciente e o corpo falante. In Scilicet: o corpo falante: sobre o inconsciente no século XXI. (pp. 19-32). São Paulo: Escola Brasileira de Psicanálise.

Starobinski, J. (2012). Le regard des statues. In L’Encre de la mélancolie. (pp. 471-498). Paris: Seuil.

Vernant, J. P. (1999). L'univers, les dieux, les hommes. Récits grecs des origines. Paris: Seuil. (La libraire du XX siècle). 